\title{
A Network Meta-Analysis Comparing Osteoporotic Fracture among Different Direct Oral Anticoagulants and Vitamin K Antagonists in Patients with Atrial Fibrillation
}

\author{
Dibbendhu Khanra ${ }^{1}$, Anindya Mukherjee ${ }^{2}$, Saurabh Deshpande ${ }^{3}$, Hassan Khan ${ }^{4}$, Sanjeev Kathuria ${ }^{5}$, Danesh Kella ${ }^{6}$, \\ Deepak Padmanabhan ${ }^{3}$ \\ ${ }^{1}$ Heart and Lung Center, New Cross Hospital, Royal Wolverhampton NHS Trust, Wolverhampton, United Kingdom \\ ${ }^{2}$ Department of Cardiology, NRS Medical College, Kolkata; \\ ${ }^{3}$ Department of Cardiology, Sri Jayadeva Institute of Cardiac Sciences and Research, Bengaluru, India \\ ${ }^{4}$ Center for the Prevention of Cardiovascular Disease, The Leon H. Charney Division of Cardiology, NYU Langone Health, NYU Robert I. \\ Grossman School of Medicine, New York, USA \\ ${ }^{5}$ Department of Cardiology, Safdarjung Hospital, New Delhi, India \\ ${ }^{6}$ Piedmont Healthcare, Greater Atlanta, USA
}

\section{Corresponding author \\ Deepak Padmanabhan \\ Department of Cardiology, Sri Jayadeva \\ Institute of Cardiac Sciences and Research, \\ Bengaluru, Karnataka 560069, India \\ Tel: $+91-7030133220$ \\ Fax: $+91-7030133220$ \\ E-mail: deepak.padmanabhan@gmail.com}

Received: January 31, 2021

Revised: April 6, 2021

Accepted: April 19, 2021
Copyright $@ 2021$ The Korean Society for Bone and Mineral Research

This is an Open Access article distributed under the terms of the Creative Commons Attribution Non-Commercial License (https://creativecommons.org/licenses/by-nc/4.0/) which permits unrestricted non-commercial use, distribution, and reproduction in any medium, provided the original work is properly cited.
Background: There are limited studies comparing the risk of osteoporosis and fractures between different direct oral anticoagulants (DOACs) and vitamin K antagonists (VKA) in non-valvular atrial fibrillation (AF). Using a network meta-analysis (NMA), we compared osteoporotic fractures among 5 different treatment arms, viz. dabigatran, rivaroxaban, apixaban, edoxaban, and VKA. Methods: Ten studies, including 5 randomized control trials and 5 population-based studies, with a total of 321,844 patients (148,751 and 173,093 in the VKA and DOAC group, respectively) with a median follow-up of 2 years, were included. A Bayesian random-effects NMA model comparing fractures among the treatment arms was performed using MetInsight V3. Sensitivity analysis excluded studies with the highest residual deviances from the NMA model. Results: The mean age of the patients was 70 years. The meta-analysis favored DOACs over VKA with significantly lower osteoporotic fracture (odds ratio [OR], 0.77; 95\% credible interval [Crl], 0.70-0.86). The NMA demonstrated that fractures were significantly lower with apixaban compared with dabigatran (OR, 0.64; 95\% Crl, 0.44-0.95); however, fractures were statistically similar between apixaban and rivaroxaban (OR, 0.84; $95 \% \mathrm{Crl}, 0.58-1.24)$ and dabigatran and rivaroxaban (OR, 1.32; 95\% Crl, 0.90-1.87). Based on the Bayesian model of NMA, the probability of osteoporotic fracture was highest with VKA and lowest with apixaban, followed by rivaroxaban, edoxaban, and dabigatran. Conclusions: The decision to prescribe anticoagulants in elderly patients with AF should be made not only based on thrombotic and bleeding risks but also on the risk of osteoporotic fracture; these factors should be considered and incorporated in contemporary cardiology practice.

Key Words: Atrial fibrillation · Factor Xa inhibitors · Network meta-analysis · Osteoporotic fractures - Vitamin K 


\section{INTRODUCTION}

Oral vitamin K antagonists (VKAs) have been traditionally used for the management and prophylaxis of venous thromboembolism (VTE) and in mitigating the risk of stroke in atrial fibrillation (AF).[1] In recent years, newer non-vitamin K-dependent anticoagulants, termed direct oral anticoagulants (DOAC) by the International Society on Thrombosis and Haemostasis, viz. Dabigatran, Rivaroxaban, Apixaban, Edoxaban are non-inferior to VKAs in treating VTE and stroke prevention in non-valvular AF with lower bleeding events.[2,3] These have the advantage of reliable anticoagulation, without the need for monitoring and minor drug/food interactions.[4]

VKAs inhibit carboxylation of osteocalcin (a principle non-collagenous protein in bone formation), decreasing bone mineral quality.[5-8] But there has been conflicting evidence on fracture risk in VKA users.[3,9-12] A recent review has suggested that DOACs might have a neutral effect on bone metabolism and fracture risk.[3] There have been some head-to-head comparisons of VKA and DOACs in terms of efficacy and safety, which have data on osteoporosis and fracture risk.[13-23] We have conducted a network analysis to compare the risk of osteoporotic fracture in nonvalvular AF (NVAF) patients taking oral anticoagulants (OAC; viz VKA, Dabigatran, Rivaroxaban, Apixaban, and Edoxaban).

\section{METHODS}

The meta-analysis consisted of NVAF patients taking anticoagulants and compared NOACs to VKA in regards to osteoporotic fracture. The network meta-analysis (NMA) was aimed to conduct direct and indirect comparisons of osteoporotic fractures among various anticoagulants (viz VKA, Dabigatran, Rivaroxaban, Apixaban, and Edoxaban). The NMA has been described by the Preferred Reporting Items for Systematic Review and Meta-Analysis (PRISMA) guideline.[24]

\section{Search strategy}

A systematic review was performed to search the existing literature published in the English language as of April 2020. Three physician-reviewers (DK, AM, SD) queried OVID Medline, EMBASE, and SCOPUS databases for published lit- erature; search terms were "atrial fibrillation", "novel oral anticoagulants", "direct oral anticoagulants", "dabigatran", "rivaroxaban", "apixaban", "edoxaban", "osteoporosis", "VKA", "vitamin K antagonist", "fracture", "osteoporotic fracture", "hip fracture,"'bone fracture,","vertebral fracture,"' wrist fracture", "bone mineral density" and combinations of these keywords (Supplementary Appendix 1). Additional literature was sought by searching the references of eligible articles. Any inter-reviewer discrepancies were resolved by a fourth reviewer (DP).

\section{Study selection}

1) Inclusion criteria

For the qualitative synthesis of the NMA, we selected only randomized controlled studies or population-based studies that directly compared individual DOACs with VKA in the AF patients and provided osteoporotic fracture as an outcome.

\section{2) Exclusion criteria}

We excluded DOAC vs. VKA studies done in the context of venous thromboprophylaxis, observational studies, studies lacking data on individual DOAC, and studies that only described osteoporosis without depicting data on fractures. Single-arm studies, case reports, case series, review articles, and abstracts presented in the conferences were also excluded.

\section{Critical appraisal}

The randomized studies were appraised with Risk of Bias 2.0 Scale,[25] and the non-randomized population-based or retrospective studies were appraised by the Newcastle Ottawa scale.[26]

\section{Data extraction}

Baseline characteristics including individual DOACs, number of participants, study design, maximum follow-up duration, age, sex, congestive heart failure, hypertension, age $\geq 75$ years, diabetes mellitus, stroke or TIA (CHADS 2$)$ score, chronic kidney disease, steroid use, and diagnosed osteoporosis or taking drugs for the treatment of osteoporosis; and fracture data were extracted from each of the selected studies. 


\section{Data analysis}

\section{1) Meta-analysis}

Descriptive statistics are presented as means and standard deviations (SDs) for continuous variables and the number of cases or percentages for dichotomous and categorical variables. Statistical analysis was performed in line with recommendations from the Cochrane Collaboration using R studio.[27] Osteoporotic fractures between DOACs and VKA have been compared using the random-effects model of DerSimonian and Laird. Heterogeneity was described as $I^{2}$ statistics; publication bias was assessed by funnel plot; covariate analysis was performed and depicted as a bubble plot.

\section{2) Network meta-analysis}

Bayesian NMA comparing osteoporotic fractures among the four DOAC (e.g., Dabigatran, Rivaroxaban, Apixaban, and Edoxaban) and VKA was performed. Network plot, league table, and rankogram were derived using MetInsight V3.[28]

Forest plot comparing fractures between individual DOACs to VKA were derived by Markov Chain Monte Carlo simulations.[29] The current version of MetInsight V3 uses the default setting for the number of simulated iterations for burn-in (5000) and the model results (20000). Dbar (posterior mean of the deviance), PD (adequate number of parameters), and DIC (sum of Dbar and PD) was calculated. Gelman-Rubin convergence was assessed for all the studies.[30] Estimates from Bayesian NMA were presented as odds ratio (OR) with $95 \%$ credible interval (Crl), i.e., the value at $2.5 \%$ and $97.5 \%$ quantiles.[31] The ranking table was derived, which showed the probability for each treatment to be ranked as the most effective treatment. The rankogram was based on the median ranking probabilities of each treatment arm.[32] The median rank is the middle iteration rank when every simulated estimate of the class is ordered.

\section{3) Inconsistency, deviance, and sensitivity analysis}

The direct, indirect, and network estimates and a Bayesian $P$-value for the related test of inconsistency between the direct and indirect evidence for each treatment comparison were derived. A residual deviance plot from the NMA model and unrelated mean effect (UME) inconsistency model for all studies was derived to assess the data points' fit- ness.[33] For both models, the larger the residual deviance, the poorer the fit of that study arm data to the respective model. Contribution for each study arm to the residual deviance was also plotted and analyzed. Ideally, each issue should contribute around one, with more significant values indicating poorer fit and higher residuals.[33] The contour plot simultaneously looked at residual deviance and leverage.[34] Leverage values outside the contour of 3 are considered poorly fitting. Sensitivity analysis was performed, excluding the population-based multi-arm studies.[34]

\section{RESULTS}

The study design of the meta-analysis has been depicted in Figure 1 PRISMA flow diagram. A total of ten studies met the inclusion criteria (5 population-based studies and 5 randomized controlled trials [RCT]),[13-17,19,21,23,35,36] all

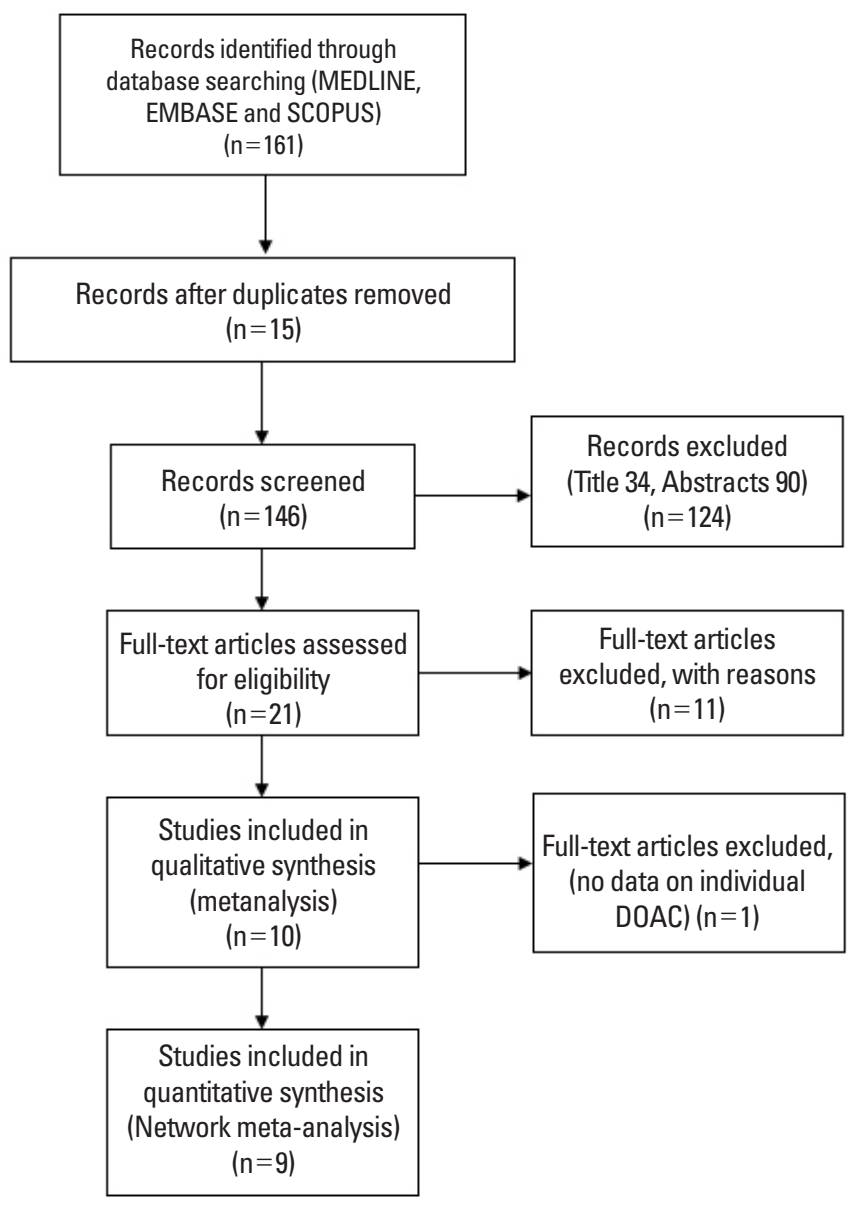

Fig. 1. Preferred Reporting Items for Systematic Review and MetaAnalysis flow diagram of patient selection. DOAC, direct oral anticoagulant. 


\begin{tabular}{|c|c|c|c|c|c|c|c|c|c|c|c|}
\hline 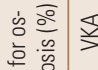 & $\stackrel{\$}{>} \infty$ & $\bar{\omega}$ & - & Б5 & g. & . & & & ' & & \\
\hline 产 & 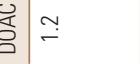 & r & g. & $\underset{+}{+}$ & $\stackrel{-}{-}$ & . & & & . & & \\
\hline 总| & 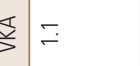 & $\stackrel{D}{\sim}$ & ò & ஓ् & $=$ & . & ' & & ' & & \\
\hline 炭 & $\begin{array}{ll}\overrightarrow{8} \\
\end{array}$ & $\bar{f}$ & $\stackrel{\circ}{\circ}$ & ळ্ & $\cong$ & . & . & & & & \\
\hline$\stackrel{s}{\sharp}$ & $\stackrel{5}{5}$ & @) & 웅 & . & $\stackrel{\sim}{\stackrel{R}{\sim}}$ & . & . & & & & \\
\hline & 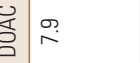 & i. & م & ' & 용 & . & ' & & & & \\
\hline & 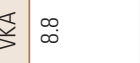 & & $\stackrel{9}{\stackrel{9}{r}}$ & $\stackrel{\circ}{ \pm}$ & ले & . & . & & $\begin{array}{l}\infty \\
\infty\end{array}$ & $\stackrel{\infty}{\stackrel{\infty}{\sigma}}$ & \\
\hline & 氙 & & $\hat{o}$ & $\stackrel{\circ}{\infty}$ & $\stackrel{g}{\sim}$ & . & & & $\begin{array}{l}\infty \\
\substack{\infty \\
\leftrightarrow 口}\end{array}$ & 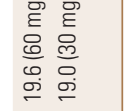 & \\
\hline & $\frac{\sigma}{5}$ & & 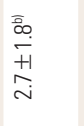 & 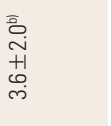 & $\underset{\substack{n \\
+1 \\
+\infty}}{+}$ & . & 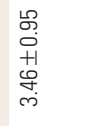 & $\underset{\text { స్ }}{\bar{m}}$ & $\underset{\frac{\pi}{i}}{\stackrel{i}{i}}$ & 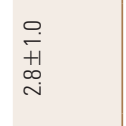 & 峞 \\
\hline & 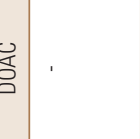 & & 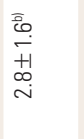 & 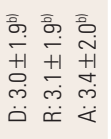 & 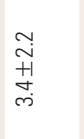 & . & 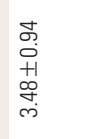 & $\underset{ల ్}{\mathbb{N}}$ & $\underset{\frac{\pi}{+}}{\frac{\pi}{i}}$ & $\underset{\substack{0 \\
+1 \\
\infty \\
i}}{\infty}$ & 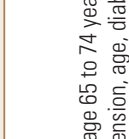 \\
\hline$\stackrel{\$}{\frac{3}{z}}$ & $\frac{1}{5}$ & $\underset{m}{\infty}$ & $\overline{\dot{y}}$ & $\begin{array}{l}\infty \\
\stackrel{\infty}{\infty}\end{array}$ & 암 & लि & के & $\stackrel{\infty}{\sim}$ & 总 & $\stackrel{\stackrel{n}{\infty}}{\stackrel{m}{m}}$ & \\
\hline & 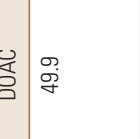 & $\bar{f}$ & $\stackrel{\infty}{q}$ & $\underset{m}{m}$ & 间 & 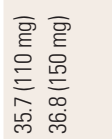 & 筞 & $\check{\check{I}}$ & 足 & 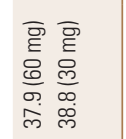 & 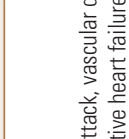 \\
\hline 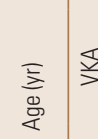 & 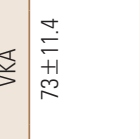 & 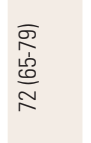 & 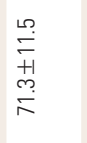 & 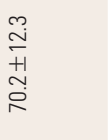 & 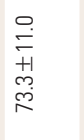 & $\begin{array}{l}\infty \\
\infty \\
\infty \\
+1 \\
0 \\
\stackrel{1}{\pi} \\
+\end{array}$ & 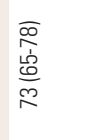 & 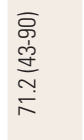 & $\begin{array}{l}\bar{\Phi} \\
\dot{0} \\
\frac{0}{2}\end{array}$ & $\begin{array}{l}\frac{0}{0} \\
\dot{d} \\
\stackrel{d}{N} \\
\end{array}$ & 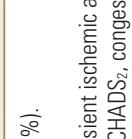 \\
\hline త্ّ & 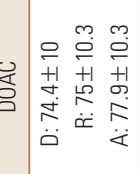 & 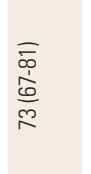 & 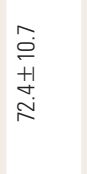 & 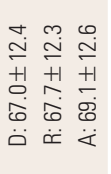 & 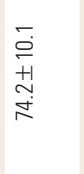 & 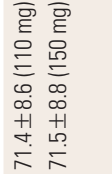 & $\begin{array}{l}\text { 总 } \\
\text { 岕 } \\
\frac{\rho}{N}\end{array}$ & 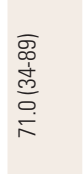 & 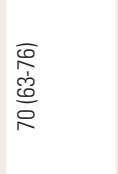 & $\begin{array}{l}\frac{a}{\alpha} \\
\dot{d} \\
\stackrel{d}{N}\end{array}$ & 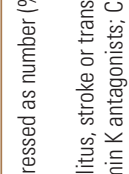 \\
\hline$\stackrel{\$}{\Rightarrow}$ & 忘 & $\stackrel{\infty}{\stackrel{一}{\simeq}}$ & $\begin{array}{l}\hat{a} \\
\sigma\end{array}$ & 通 & 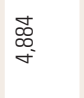 & & $\stackrel{m}{\stackrel{m}{n}}$ & ஜृ & $\begin{array}{l}\bar{g} \\
\dot{\sigma o}\end{array}$ & 足 & 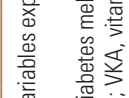 \\
\hline 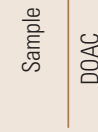 & 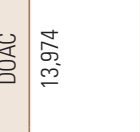 & 离 & $\underset{\partial}{\grave{\sigma}}$ & $\begin{array}{l}\text { 怘 } \\
\stackrel{0}{\infty}\end{array}$ & 怘 & 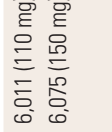 & $\stackrel{m}{=}$ & ஜृ & $\frac{\pi}{\sigma}$ & 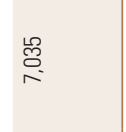 & 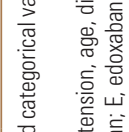 \\
\hline 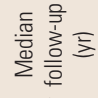 & $\bar{n}$ & $\sim$ & $\stackrel{\sim}{\sim}$ & $\bar{i}$ & 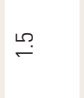 & $\sim$ & $\bar{i}$ & $\stackrel{\infty}{\infty}$ & & $\stackrel{\infty}{i}$ & 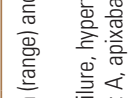 \\
\hline $\begin{array}{l}\text { Zे } \\
\text { 言 }\end{array}$ & 总 뫃 & 言 总 & 頦 & 崩 & & 接言总 & 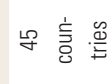 & & و 言兽 & go 言兽 & \\
\hline 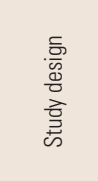 & 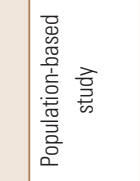 & 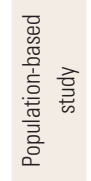 & 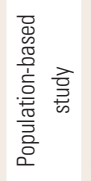 & 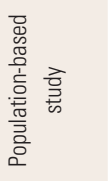 & 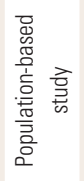 & 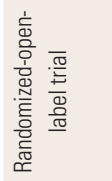 & 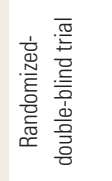 & 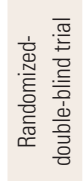 & 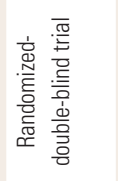 & 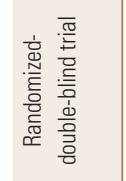 & 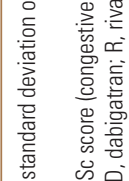 \\
\hline 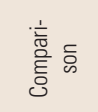 & 兽 & 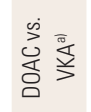 & 岕 & 岁 & 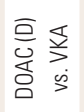 & $\begin{array}{l}\text { 可弯 } \\
\text { 产品 }\end{array}$ & 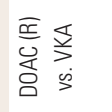 & 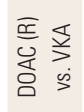 & 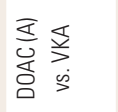 & 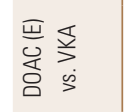 & 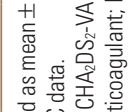 \\
\hline$\stackrel{\bar{\varpi}}{\check{\varpi}}$ & ప్రి & 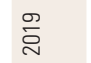 & ఫ్ది & ప్రి & 言 & 酎 & 言 & స్ & 亏్ & ఏ్ & 产㕷 \\
\hline 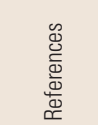 & 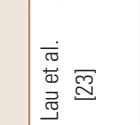 & 埡 & 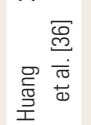 & 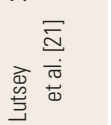 & 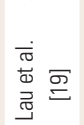 & 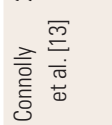 & 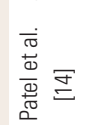 & 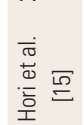 & 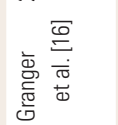 & 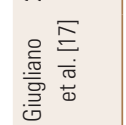 & 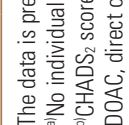 \\
\hline
\end{tabular}


of which were included in the qualitative analysis (metaanalysis). Critical appraisal of the studies is depicted in Supplementary Appendix 2, which suggests good quality of population-based studies (more than 5 stars in the Newcastle-Ottawa Scale) and RCTs (more than 5 points in RoB 2.0 scale).

\section{Baseline parameters}

Overall, patients studied in this meta-analysis had their mean age above 70 years of age (Table 1). A cohort of Lutsey et al. [21] was slightly younger than the other studies. Patients with osteoporosis, or osteoporosis drugs were maximum in the population cohort reported by Lutsey et al.

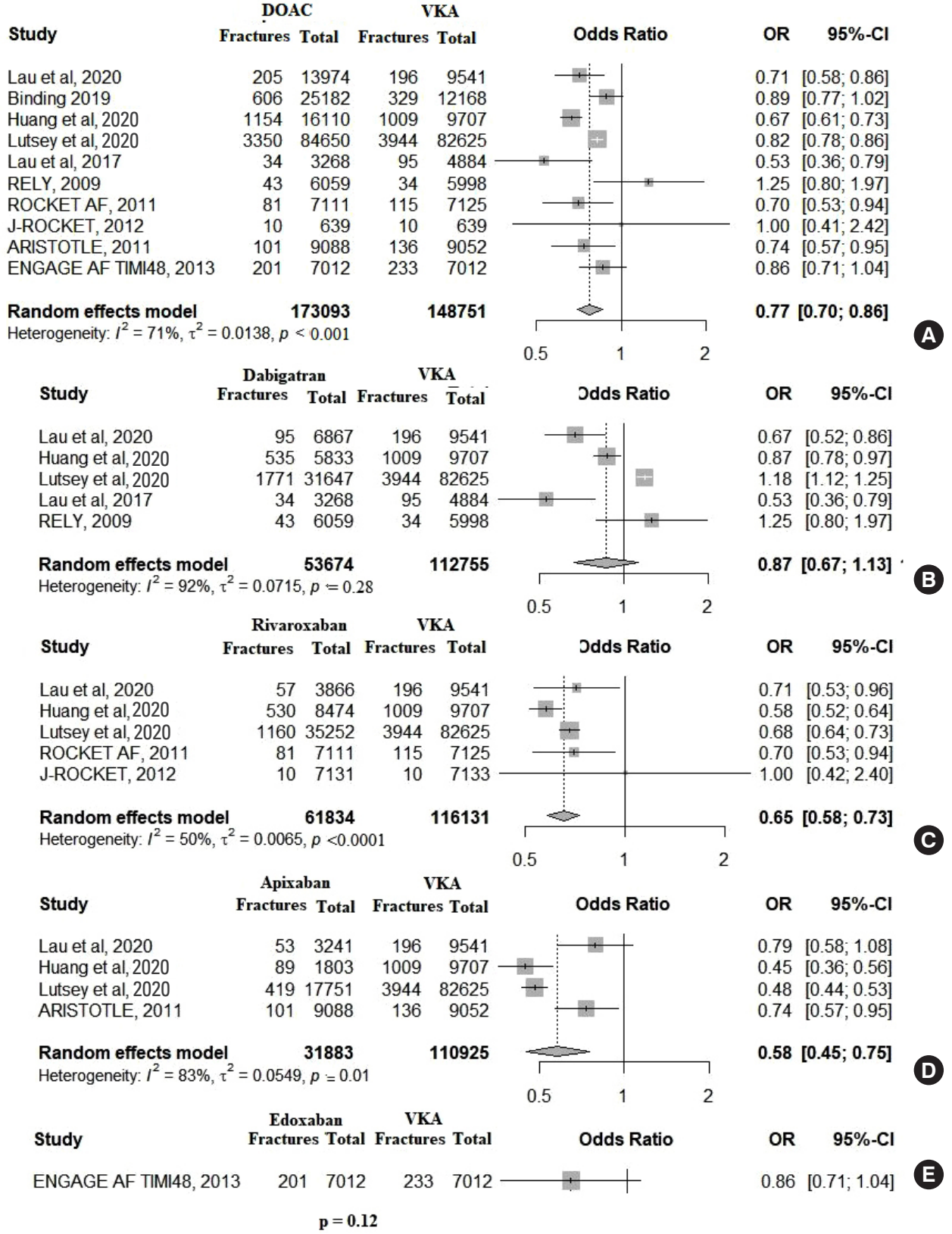

Fig. 2. (A) Forest plot depicting the comparison of total fractures with vitamin $\mathrm{K}$ antagonists (VKA) and direct oral anticoagulant (DOAC) among different studies in random effect and inverse variance method. Estimates were expressed in odds ratio (OR) with 95\% confidence interval (CI). Heterogeneity was expressed in $\mathrm{I}^{2}$ and tau ${ }^{2} . P<0.05$ was set as level of significance. Sub-group analysis showing comparison of fractures between individual (B) dabigatran and VKA, (C) rivaroxaban and VKA, (D) apixaban and VKA, (E) edoxaban and VKA. Binding et al. [35], 2019 was excluded from sub-group analysis as it did not report DOAC-specific fracture data. 
[21] in 2019. Overall, patients on steroids were low among the study cohorts. The baseline parameters, including age, the proportion of female genders, chronic kidney diseases, and osteoporosis patients and therapy for osteoporosis, were similar between DOAC and VKA groups (Table 1).

\section{1) DOC vs. VKA: Meta-analysis}

The meta-analysis directly comparing osteoporotic fractures between DOAC and VKA favored DOAC (OR $[95 \% \mathrm{Cl}$, $0.77(0.70-0.86) ; P<0.0001)$ than VKA (Fig. 2A). However, the heterogeneity of the result was $71 \%$, and that could not be explained by publication bias (Supplementary Appendix 3), study design (Supplementary Appendix 4), or follow-up duration (Supplementary Appendix 5). Subgroup analysis with direct comparison of osteoporotic fractures in individual DOACs with respect to VKA also revealed to be significantly lower (Fig. 2B-E). Notably, heterogeneity was maximum (92\%) with Dabigatran and appears to be contributed by the large population-based study by Lutsey et al. [21], which reported significantly higher osteoporotic fractures in Dabigatran in comparison to VKA (OR $[95 \% \mathrm{Cl}$, 1.18 [1.12-1.25]). Also, RELY showed a higher trend of fractures with Dabigatran (OR [95\% Cl], 1.25 [0.80-1.97]), however, outside the realm of statistical significance.

\section{2) Comparison among individual DOACs: NMA (1) Data summary}

A total of 321,844 patients were included in the metaanalysis (148,751 in the VKA group; 173,093 in DOAC group) with a median follow-up of 2 years. In contrast, 9 were in-

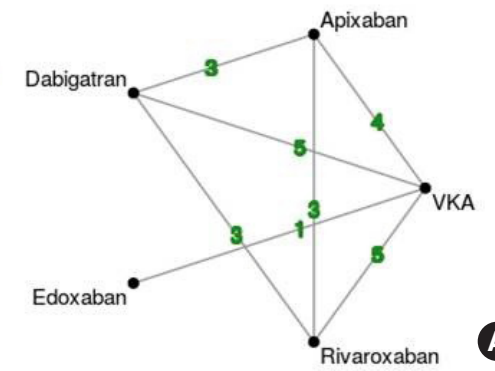

\begin{tabular}{llllll} 
& Apixaban & Dabigatran & Edoxaban & Rivaroxaban & VKA \\
\hline Apixaban & Apixaban & $1.56(1.05,2.26)$ & $1.49(0.67,3.2)$ & $1.19(0.81,1.74)$ & $1.73(1.22,2.42)$ \\
\hline Dabigatran & $0.64(0.44,0.95)$ & Dabigatran & $0.95(0.44,2.06)$ & $0.76(0.53,1.12)$ & $1.11(0.81,1.53)$ \\
\hline Edoxaban & $0.67(0.31,1.5)$ & $1.05(0.49,2.27)$ & Edoxaban & $0.8(0.37,1.76)$ & $1.17(0.58,2.37)$ \\
\hline Rivaroxaban & $0.84(0.58,1.24)$ & $1.32(0.9,1.87)$ & $1.25(0.57,2.68)$ & Rivaroxaban & $1.46(1.05,2)$ \\
\hline VKA & $0.58(0.41,0.82)$ & $0.9(0.65,1.23)$ & $0.86(0.42,1.72)$ & $0.68(0.5,0.96)$ & VKA
\end{tabular}
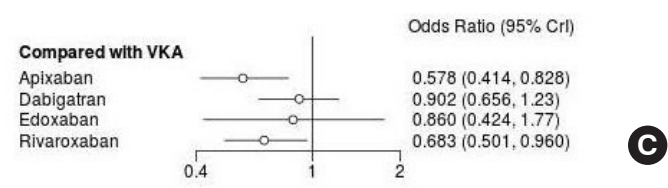

\begin{tabular}{lccccc} 
& Rank 1 & Rank 2 & Rank 3 & Rank 4 & Rank 5 \\
\hline Apixaban & 0.72813 & 0.21776 & 0.04723 & 0.00570 & 0.001 \\
\hline Dabigatran & 0.00549 & 0.04320 & 0.36552 & 0.40640 & 0.179 \\
\hline Edoxaban & 0.12945 & 0.14269 & 0.27294 & 0.16145 & 0.293 \\
\hline Rivaroxaban & 0.13673 & 0.59247 & 0.23215 & 0.03222 & 0.006 \\
\hline VKA & 0.00021 & 0.00387 & 0.08216 & 0.39422 & 0.519
\end{tabular}

\begin{tabular}{|cl|}
\hline Rank & Intervention \\
\hline 1 & Apixaban \\
\hline 2 & Rivaroxaban \\
\hline 3 & Edoxaban \\
\hline 4 & Dabigatran \\
\hline 5 & VKA \\
\hline
\end{tabular}

Fig. 3. Network meta-analysis comparing fracture events among 5 treatment arms. (A) Network plot where each node on the plot represents an individual intervention (dabigatran, rivaroxaban, apixaban, edoxaban, and vitamin $\mathrm{K}$ antagonists [VKA]) with connecting lines between nodes indicating number of trials making each comparison. (B) League table showing Bayesian comparison of all treatment pairs: the table displays the results for all treatment pairs in both the upper triangle and lower triangle, but with the comparison switched over. For both above and below the leading diagonal, the results are for the treatment at the top of the same column vs. treatment at the left hand side of the same row. (C) Bayesian random effect consistency model forest plot of the pooled effect estimates of fractures expressed in odds ratio and 95\% credible interval (Crl) for individual direct oral anticoagulants (DOACs) compared to VKA. (D) Ranking probability table for all studies showing probability for each treatment at each rank expressed in percentage. (E) Rankogram showing median rank chart of intervention arms with all studies included in the network meta-analysis model. For treatment rankings, smaller outcome values were set as desirable. 
cluded in the quantitative analysis (NMA) in which 297,480 subjects were included (136,583 in the VKA group; 147,911 in DOAC group). The study by Binding et al. [35] was excluded from the NMA due to lack of individual DOAC data (Supplementary Appendix 6). The NMA compared 5 treatment arms: Dabigatran, Rivaroxaban, Apixaban, Edoxaban, and VKA. Notably, although there were 62 -arm studies [13$17,19]$ and 3 multi-arm studies,[21,23,36] data on Edoxaban was present only in one RCT.[17] The network plot with studies between each treatment arm is depicted in Figure 3A. Of note, only ENGAGE TIMI 48 [17] had fracture data of Edoxaban and no population-based studies evaluated Edoxaban.

\section{(2) Comparison of different treatment arms}

The league-table derived by the Bayesian model compared the 5 treatment arms is depicted in Figure 3B. Osteoporotic fractures were significantly lower with Apixaban in comparison to Dabigatran (OR [95\% Crl], 0.64 [0.440.95]). Node-split model demonstrated significant inconsistency between the estimates from direct and indirect comparison ( $P$ of 0.48 ). Osteoporotic fractures were statistically similar between Apixaban and Rivaroxaban (OR [95\% Crl], 0.84 [0.58-1.24]); and Dabigatran and Rivaroxaban (OR [95\% Crl], 1.32 [0.90-1.87]). Node-split model did not demonstrate any significant inconsistencies in these comparisons ( $P$ of 0.76 and 0.52 respectively) (Supplementary Appendix 7).

\section{(3) Forest plot}

The forest plot (Fig. 3C) comparing individual DOACs to VKA demonstrated that Apixaban (OR [95\% Crl], 0.58 [0.41$0.82])$ and Rivaroxaban (OR [95\% Crl], 0.68 [0.50-0.96]) were associated with significantly lower fractures when compared to VKA (Fig. 3C). Fractures associated with Dabigatran (OR [95\% Crl], 0.90 [0.65-1.23]) and Edoxaban (OR [95\% $\mathrm{Crl}], 0.86$ [0.42-1.77]) were statistically similar in comparison to VKA. Study SD $(95 \% \mathrm{Crl})$ in log-odds scale was 0.33 (0.18-0.58). Dbar, PD and DIC were 24.42, 22.13, 46.56, respectively. Notably, a DIC of more than 5 supports our choice of the Bayesian model for NMA. The Gelman-Rubin convergence assessment plots for each treatment comparison were found to be reaching stabilities around 1, which is suggestive of a good fit of the Bayesian NMA model (Supplementary Appendix 8).

\section{(4) Ranking treatment arms}

The highest probability of rankings (lower the better) in regards to osteoporotic fractures was with Apixaban (90\%), Rivaroxaban (76\%), Edoxaban (53\%), VKA (67\%), and Dabigatran (74\%) as rank 1, rank 2, rank 3, rank 4, and ranked 5 respectively (Fig. 3D). However, when orders of median
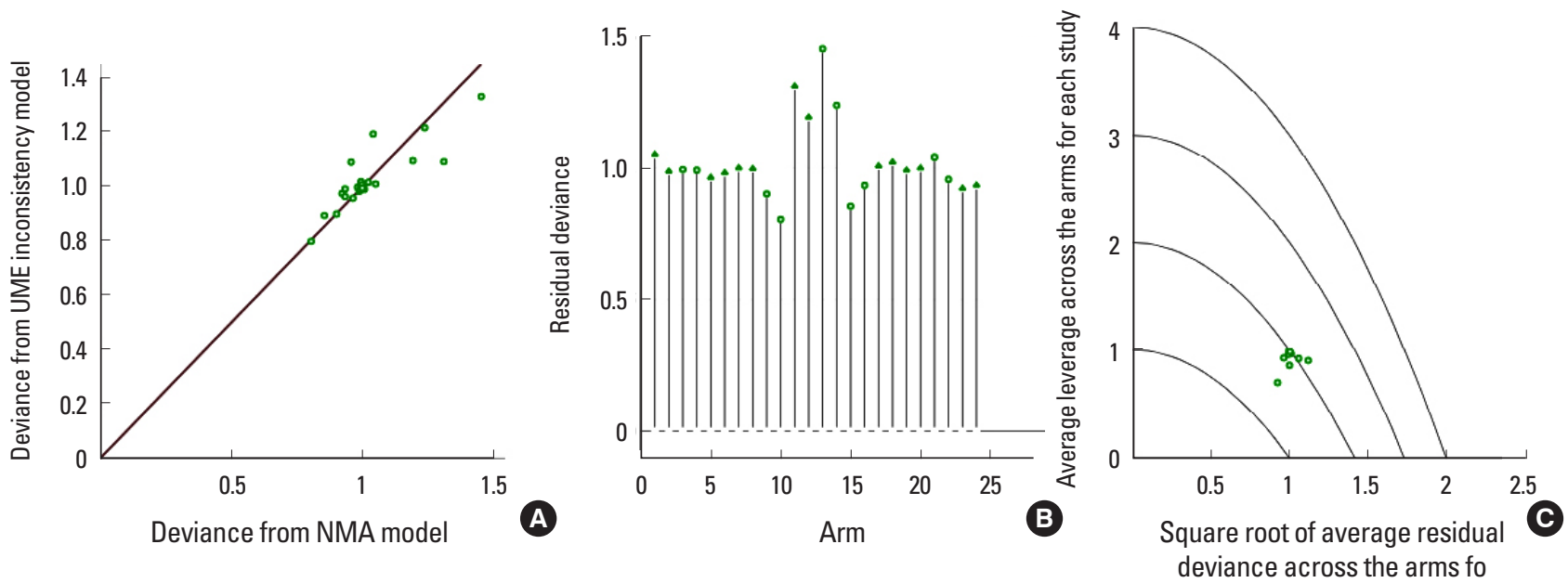

Fig. 4. Deviance report: (A) residual deviance from primary network meta-analysis (NMA) model are plotted against the residual deviance from the unrelated mean effect (UME) inconsistency model for each study arm separately in the analysis. For both models, the larger the residual deviance, the poorer the fit of that study arm data to the respective model. The values of residual deviances for each trial arm from NMA and UME model are mentioned in Supplementary Appendix 8; (B) plot derived from primary NMA model showing contribution for each study arm to the residual deviance; arms from the same study are ordered from left to right; (C) the contour plot looking at residual deviance and leverage (which is a statistical measure of influence of a data point on model estimation) simultaneously. 
ranking probabilities were plotted (rankogram), VKA and Apixaban were found to have the highest and lowest median probability of osteoporotic fractures (Fig. 3E).

\section{(5) Residual deviances}

Residual deviances from NMA model and UME inconsistency model for all the treatment arms were plotted (Fig. 4A). Of note, UMA model may not handle multi-arm trials correctly. Lau et al. [19] and Lau et al. [23] were found to have the highest residual deviances from NMA model (Supplementary Appendix 9); however, the value of the deviances was less than 2 (Fig. 4B) and the leverage values were less than 3 (Fig. 4C) and thus suggest that the amplitude of deviances from the NMA model were not great.

\section{(6) Sensitivity analyses}

Sensitivity analysis was performed excluding Lau et al. [19] and Lau et al. [23], which resulted in similar results with Apixaban causing the least osteoporotic fractures overall, however, estimate comparing fractures between Dabigatran and VKA rose to OR (95\% Crl), 1.12 (0.85-1.52), The node-split model demonstrated significant inconsistency $(P=0.47)$ between direct and indirect comparisons of estimates of comparing fractures between Apixaban and Rivaroxaban. This also resulted in the change in rankogram with Dabigatran being the highest one associated to fractures, even more than VKA (Supplementary Appendix 10).

\section{(7) Sub-group analysis}

Looking at the above-mentioned studies, both of them were population-based ones, and thus, a subgroup analysis was conducted with a focus to determine any difference in results when population-based studies and RCTs were analysed separately. With 5 RCTs [13-17] totalling 72,721 patients, Apixaban and Rivaroxaban ranked jointly associated with the lowest fractures and Dabigatran as the highest (Supplementary Appendix 11). Whereas, with only four population-based studies $[21,23,35,36]$ totalling 224,759 patients the outcome remained similar to the overall NMA results (Supplementary Appendix 11). This proves that the NMA model which was used to derive the ranks of treatments in regard to fractures were driven by the population studies which were larger and multi-arm. However, fracture data were taken retrospectively in those population based studies and patient profile and their concurrent medications can affect the result. Of note, no population study evaluated Edoxaban, and thus the estimates for Edoxaban solely relied on the ENGAGE TIMI 48.[17]

\section{DISCUSSION}

This is the most extensive study, based on sample size, comparing the osteoporotic fractures amongst different types of anticoagulants, and it is the first NMA to compare 5 other treatment arms in patients requiring OACs for NVAF. Our results suggest that osteoporotic fractures are lower with DOACs than VKA. Apixaban is associated with the least fracture risk in comparison to other DOACs in the NMA.

DOACs can lead to lesser osteoporosis than VKA due to several postulated reasons. Vitamin $\mathrm{K}$ is known co-factor $\gamma$-carboxylase, which is essential for $\gamma$-carboxylation of osteocalcin, without which it cannot bind to mineral hydroxyapatite and lacks structural integrity. VKA affects the mineralization of the bone and thus predisposes to osteoporosis and fractures, whereas DOACs do not interfere with vitamin K-dependent metabolism. Fusaro et al. [37] found in an in-vivo study that rats receiving Dabigatran had increased bone volume, lesser bone turnover, and reduced trabecular separation.[38] Rivaroxaban may positively affect the healing of fracture as demonstrated by large callus formation and increased bone mineral density in a femur fracture rat model.[38] Edoxaban showed no impact on osteocalcin in rats even at a high dose of $54 \mathrm{mg} / \mathrm{kg}$.[38] These data support the protective effect of DOACs on bone health; however, the exact role of DOACs in bone mineral metabolism is still unclear.[38] Warfarin treatment was accompanied by a restriction of Vitamin K-rich foods like green leafy vegetables to achieve optimum anticoagulation. Vitamin $\mathrm{K}$ is essential for many stages of bone metabolism. Thus, poor vitamin $\mathrm{K}$ status results in high fracture risk due to low bone mass.[38]

\section{DOAC vs. VKA}

Our results are similar to the multi-methodological data mining analysis from real-world data analysis from the US Food and Drug Administration Event Reporting System and Japanese administration claims database, which revealed that warfarin use, not DOACs, is significantly associated with osteoporosis or use of bisphosphonate regard- 
less of sex difference.[22] In our meta-analysis, the age, the proportion of female gender, chronic kidney disease, and osteoporosis were similar between the DOAC and VKA groups. Signorelli et al. [3] compared the effect of heparin, VKA, and DOACs in bone metabolism. They found that unfractionated heparin and VKA have the maximum impact, whereas DOACs were found to neutral in this regard. The patients on unfractionated heparin had the highest fracture incidence, but DOACs had no increased fracture risk. $[39,40]$

In another meta-analysis comparing osteoporotic fractures between VKA and DOAC, it was found that DOAC was associated with lower osteoporotic fractures than VKA in NVAF patients but not for VTE prophylaxis.[38] However, our meta-analysis results are more robust as the sample size was more significant $(89,549$ vs. 321,844$)$ and comprised of extensive population-based studies.[38] The studies included in our meta-analysis had long follow-up durations, with a median of 2 years, except the J-ROCKET research, which only reported short-term outcomes (30 days). [16] In subgroup analysis, we showed that the relationship of DOAC vs. VKA in osteoporosis remains the same irrespective of the study's follow-up duration and design (Randomized vs. population-based study). Our meta-analysis demonstrated no difference among the VKA and DOAC cohorts in terms of age, gender, chronic kidney disease, steroids, and osteoporosis. Thus, the comparison of fractures is not affected by any of these variables.

\section{Comparison among individual DOACs}

Previous studies comparing osteoporotic fracture risk amongst DOACs have yielded mixed results. In the most extensive population-based study by Lutsey et al. [21], headto-head DOAC comparisons yielded no statistically significant fracture risk differences. However, findings suggested that Apixaban was the most advantageous. The study by Lau et al. [23] did not show any statistically significant difference in risk of osteoporotic fractures in a head-to-head comparison of the DOACs. In contrast, Huang et al. [36], reported that Rivaroxaban and Apixaban were associated with the lowest fracture risk compared to warfarin. Similarly, another study on the risk of osteoporosis found that compared to Dabigatran, both Rivaroxaban and Apixaban were associated with a lower risk of osteoporosis.[41] There was no significant difference in osteoporosis risk when com- paring Apixaban and Rivaroxaban. Moreover, the association between DOAC use and a lower incidence of osteoporosis seemed stronger in those with a more extended treatment duration (more than 180 days).

In our NMA, Apixaban was found to have lower fracture risk by $42 \%$ than VKA and $36 \%$ compared to Dabigatran. In comparison with VKA, Rivaroxaban showed a 32\% lower fracture risk. The propensity of fracture was ranked as (lowest to highest) Apixaban, Rivaroxaban, Edoxaban, Dabigatran, and VKA. This is a novel finding in our study and is tested as consistent indirect and indirect comparisons.

\section{Limitations}

Our analysis had few shortcomings, including a lack of individual patient data, which restrained us from doing a network meta-regression of the baseline parameters, including existing osteoporosis or bisphosphonate use. Our analysis was focused on the use of oral anticoagulants in patients with NVAF, so it cannot be directly extrapolated to use in other disease processes (e.g., VTE prophylaxis) where oral anticoagulants are also used. We could not compare site-specific (e.g., hip fracture vs. vertebral fracture, unlike hip fractures, most vertebral fractures occur without falls) or dose-specific (e.g., standard dose vs. lower dose DOAC) fracture data. Studies on Edoxaban for osteoporosis and fracture may be under-represented in our NMA.

\section{CONCLUSIONS}

DOACs are associated with a lower risk of osteoporotic fracture than VKA among patients with NVAF. This is the first of its kind NMA comparing individual DOACs amongst themselves and VKA. It suggests that Apixaban is associated with the lowest odds of osteoporotic fracture risk amongst all the currently available DOACs, whereas Dabigatran was associated with the highest odds of fractures. Future studies are needed to understand some of the DOAC's protective mechanisms against fractures at the cellular levels. The decision for the prescription of anticoagulants in elderly patients with $\mathrm{AF}$ should be made not only on the basis of thrombotic and bleeding risks but also the risks of osteoporotic fracture should be considered and incorporated in the contemporary cardiology practice. 


\section{DECLARATIONS}

\section{Acknowledgments}

We would like to thank Danielle Gerber from the Mayo Clinic Library service for conducting the extensive literature search.

\section{Funding}

The authors received no financial support for this article.

\section{Ethics approval and consent to participate Not applicable.}

\section{Conflict of interest}

No potential conflict of interest relevant to this article was reported.

\section{ORCID}

Dibbendhu Khanra https://orcid.org/0000-0002-5446-4498 Sanjeev Kathuria https://orcid.org/0000-0002-7860-8564 Danesh Kella https://orcid.org/0000-0003-4657-1944 Deepak Padmanabhan

https://orcid.org/0000-0002-9577-1611

\section{REFERENCES}

1. Julia S, James U. Direct oral anticoagulants: A quick guide. Eur Cardiol 2017;12:40-5. https://doi.org/10.15420/ecr.2017: 11:2.

2. Barnes GD, Ageno W, Ansell J, et al. Recommendation on the nomenclature for oral anticoagulants: communication from the SSC of the ISTH: reply. J Thromb Haemost 2015; 13:2132-3. https://doi.org/10.1111/jth.13136.

3. Signorelli SS, Scuto S, Marino E, et al. Anticoagulants and osteoporosis. Int J Mol Sci 2019;20. https://doi.org/10.3390/ ijms20215275.

4. Mayer F, Kirchmayer U, Coletta P, et al. Safety and effectiveness of direct oral anticoagulants versus vitamin $\mathrm{K}$ antagonists: Pilot implementation of a near-real-time monitoring program in Italy. J Am Heart Assoc 2018;7:e008034. https://doi.org/10.1161/jaha.117.008034.

5. Kavukcuoglu NB, Patterson-Buckendahl P, Mann AB. Effect of osteocalcin deficiency on the nanomechanics and chemistry of mouse bones. J Mech Behav Biomed Mater 2009; 2:348-54. https://doi.org/10.1016/j.jmbbm.2008.10.010.
6. Rey-Sánchez P, Lavado-García JM, Canal-Macías ML, et al. Ultrasound bone mass in schizophrenic patients on antipsychotic therapy. Hum Psychopharmacol 2009;24:49-54. https://doi.org/10.1002/hup.984.

7. Sugiyama T, Takaki T, Sakanaka K, et al. Warfarin-induced impairment of cortical bone material quality and compensatory adaptation of cortical bone structure to mechanical stimuli. J Endocrinol 2007;194:213-22. https:// doi.org/10.1677/joe-07-0119.

8. Sugiyama T, Kawai S. Carboxylation of osteocalcin may be related to bone quality: a possible mechanism of bone fracture prevention by vitamin K. J Bone Miner Metab 2001; 19:146-9. https://doi.org/10.1007/s007740170034.

9. Caraballo PJ, Gabriel SE, Castro MR, et al. Changes in bone density after exposure to oral anticoagulants: a meta-analysis. Osteoporos Int 1999;9:441-8. https://doi.org/10.1007/ s001980050169.

10. Veronese N, Bano G, Bertozzo G, et al. Vitamin K antagonists' use and fracture risk: results from a systematic review and meta-analysis. J Thromb Haemost 2015;13:166575. https://doi.org/10.1111/jth.13052.

11. Guyatt GH, Oxman AD, Kunz R, et al. Going from evidence to recommendations. BMJ 2008;336:1049-51. https://doi. org/10.1136/bmj.39493.646875.AE.

12. Fiordellisi W, White K, Schweizer M. A systematic review and meta-analysis of the association between vitamin $\mathrm{K}$ antagonist use and fracture. J Gen Intern Med 2019;34:30411. https://doi.org/10.1007/s11606-018-4758-2.

13. Connolly SJ, Ezekowitz MD, Yusuf S, et al. Dabigatran versus warfarin in patients with atrial fibrillation. N Engl J Med 2009;361:1139-51. https://doi.org/10.1056/NEJMoa0905561.

14. Patel MR, Mahaffey KW, Garg J, et al. Rivaroxaban versus warfarin in nonvalvular atrial fibrillation. N Engl J Med 2011; 365:883-91. https://doi.org/10.1056/NEJMoa1009638.

15. Hori M, Matsumoto M, Tanahashi N, et al. Rivaroxaban vs. warfarin in Japanese patients with atrial fibrillation - the J-ROCKET AF study -. Circ J 2012;76:2104-11. https://doi. org/10.1253/circj.cj-12-0454.

16. Granger CB, Alexander JH, McMurray JJ, et al. Apixaban versus warfarin in patients with atrial fibrillation. $N$ Engl J Med 2011;365:981-92. https://doi.org/10.1056/NEJMoa 1107039.

17. Giugliano RP, Ruff CT, Braunwald E, et al. Edoxaban versus warfarin in patients with atrial fibrillation. N Engl J Med 
2013;369:2093-104. https://doi.org/10.1056/NEJMoa1310907.

18. Bengtson LGS, Lutsey PL, Chen LY, et al. Comparative effectiveness of dabigatran and rivaroxaban versus warfarin for the treatment of non-valvular atrial fibrillation. J Cardiol 2017;69:868-76. https://doi.org/10.1016/j.jjcc.2016.08.010.

19. Lau WC, Chan EW, Cheung CL, et al. Association between dabigatran vs warfarin and risk of osteoporotic fractures among patients with nonvalvular atrial fibrillation. JAMA 2017;317:1151-8. https://doi.org/10.1001/jama.2017.1363.

20. Norby FL, Bengtson LGS, Lutsey PL, et al. Comparative effectiveness of rivaroxaban versus warfarin or dabigatran for the treatment of patients with non-valvular atrial fibrillation. BMC Cardiovasc Disord 2017;17:238. https://doi. org/10.1186/s12872-017-0672-5.

21. Lutsey PL, Norby FL, Ensrud KE, et al. Association of anticoagulant therapy with risk of fracture among patients with atrial fibrillation. JAMA Intern Med 2020;180:245-53. https://doi.org/10.1001/jamainternmed.2019.5679.

22. Yokoyama S, leda S, Nagano M, et al. Association between oral anticoagulants and osteoporosis: Real-world data mining using a multi-methodological approach. Int J Med Sci 2020;17:471-9. https://doi.org/10.7150/ijms.39523.

23. Lau WCY, Cheung CL, Man KKC, et al. Association between treatment with apixaban, dabigatran, rivaroxaban, or warfarin and risk for osteoporotic fractures among patients with atrial fibrillation: A population-based cohort study. Ann Intern Med 2020;173:1-9. https://doi.org/10.7326/ m19-3671.

24. Liberati A, Altman DG, Tetzlaff J, et al. The PRISMA statement for reporting systematic reviews and meta-analyses of studies that evaluate healthcare interventions: explanation and elaboration. BMJ 2009;339:b2700. https://doi. org/10.1136/bmj.b2700.

25. Sterne JAC, Savović J, Page MJ, et al. RoB 2: a revised tool for assessing risk of bias in randomised trials. BMJ 2019; 366:14898. https://doi.org/10.1136/bmj.14898.

26. Wells GA, Shea B, O'Connell D, et al. The Newcastle-Ottawa scale (NOS) for assessing the quality of nonrandomised studies in meta-analyses. 2009 [cited by 2009 Feb 1]. Available from: https://www.ohri.ca/programs/clinical_epidemiology/oxford.asp

27. Sommer H, Schwarzer G, Rücker G. Use R! an introduction to meta-analysis with R. Filtering the information overload for better decisions. The 23rd Cochrane Colloquium;
2015 Oct 3-7; Vienna, AT: John Wiley \& Sons.

28. Owen RK, Bradbury N, Xin Y, et al. Metalnsight: An interactive web-based tool for analyzing, interrogating, and visualizing network meta-analyses using R-shiny and netmeta. Res Syn Meth 2019;10:569-81. https://doi.org/10.1002/ jrsm.1373.

29. van Ravenzwaaij D, Cassey P, Brown SD. A simple introduction to Markov Chain Monte-Carlo sampling. Psychon Bull Rev 2018;25:143-54. https://doi.org/10.3758/s13423016-1015-8.

30. Brooks SP, Gelman A. General methods for monitoring convergence of iterative simulations. J Comput Graph Stat 1998;7:434-55. https://doi.org/10.1080/10618600.1998.1 0474787.

31. Hu D, O'Connor AM, Wang C, et al. How to conduct a bayesian network meta-analysis. Front Vet Sci 2020;7:271. https: //doi.org/10.3389/fvets.2020.00271.

32. Cope S, Jansen JP. Quantitative summaries of treatment effect estimates obtained with network meta-analysis of survival curves to inform decision-making. BMC Med Res Methodol 2013;13:147. https://doi.org/10.1186/1471-228813-147.

33. Dias S, Welton NJ, Sutton AJ, et al. Evidence synthesis for decision making 4: inconsistency in networks of evidence based on randomized controlled trials. Med Decis Making 2013;33:641-56. https://doi.org/10.1177/0272989x12455847.

34. Wheeler DC, Hickson DA, Waller LA. Assessing local model adequacy in bayesian hierarchical models using the partitioned deviance information criterion. Comput Stat Data Anal 2010;54:1657-71. https://doi.org/10.1016/j.csda.2010. 01.025.

35. Binding C, Bjerring Olesen J, Abrahamsen B, et al. Osteoporotic fractures in patients with atrial fibrillation treated with conventional versus direct anticoagulants. J Am Coll Cardiol 2019;74:2150-8. https://doi.org/10.1016/j.jacc.2019. 08.1025 .

36. Huang HK, Liu PP, Hsu JY, et al. Fracture risks among patients with atrial fibrillation receiving different oral anticoagulants: a real-world nationwide cohort study. Eur Heart J 2020;41:1100-8. https://doi.org/10.1093/eurheartj/ehz952.

37. Fusaro M, Dalle Carbonare L, Dusso A, et al. Differential effects of dabigatran and warfarin on bone volume and structure in rats with normal renal function. PLoS One 2015;10: e0133847. https://doi.org/10.1371/journal.pone.0133847. 
38. Gu ZC, Zhou LY, Shen L, et al. Non-vitamin K antagonist oral anticoagulants vs. warfarin at risk of fractures: A systematic review and meta-analysis of randomized controlled trials. Front Pharmacol 2018;9:348. https://doi. org/10.3389/fphar.2018.00348.

39. Dahlman TC. Osteoporotic fractures and the recurrence of thromboembolism during pregnancy and the puerperium in 184 women undergoing thromboprophylaxis with heparin. Am J Obstet Gynecol 1993;168:1265-70. https:// doi.org/10.1016/0002-9378(93)90378-v.

40. Treceño-Lobato C, Jiménez-Serranía MI, Martínez-García R, et al. New anticoagulant agents: Incidence of adverse drug reactions and new signals thereof. Semin Thromb Hemost 2019;45:196-204. https://doi.org/10.1055/s-0038-1657783.

41. Huang HK, Liu PP, Hsu JY, et al. Risk of osteoporosis in patients with atrial fibrillation using non-vitamin $\mathrm{K}$ antagonist oral anticoagulants or warfarin. J Am Heart Assoc 2020; 9:e013845. https://doi.org/10.1161/jaha.119.013845. 
Supplementary Appendix 1. Search strategy

\begin{tabular}{|c|c|}
\hline Database & Search query \\
\hline \multicolumn{2}{|c|}{ Ovid MEDLINE } \\
\hline$\# 1$ & exp Osteoporosis \\
\hline \#2 & exp Fractures, Bone \\
\hline \#3 & Bone Density \\
\hline \#4 & (osteopor* $^{*}$ or fracture* ${ }^{*}$ (bone adj2 density)). ab,kf,ti \\
\hline$\# 5$ & or/\#1-\#4 \\
\hline \#6 & Atrial Fibrillation \\
\hline$\# 7$ & exp Anticoagulants \\
\hline \#8 & $\begin{array}{l}\text { (warfarin or coumadin or acenocoumarol or Rivaroxaban or edoxaban or Apixaban or dabigatran or anticoagula* or anti-coagu- } \\
\left(\mathrm{a}^{*}\right) \cdot \mathrm{ab}, \mathrm{kw}, \mathrm{nm}, \mathrm{ti} \text {. }\end{array}$ \\
\hline$\# 9$ & or/\#9-\#10 \\
\hline$\# 10$ & (oral ${ }^{*}$ or DOAC).ab,kw,ti. \\
\hline$\# 11$ & $\# 5$ and \#8 and \#11 and \#12 \\
\hline \multicolumn{2}{|l|}{ EMBASE } \\
\hline$\# 1$ & exp osteoporosis \\
\hline \#2 & exp fracture \\
\hline \#3 & exp bone density \\
\hline$\# 4$ & (osteopor* or fracture* or (bone adj2 density)).ab,kw,ti. \\
\hline$\# 5$ & or/\#1-\#4 \\
\hline \#6 & exp atrial fibrillation \\
\hline$\# 7$ & (fibril* or AFib or AF).ab,kw,ti. \\
\hline \#8 & or/\#6-\#7 \\
\hline$\# 9$ & exp anticoagulant agent \\
\hline$\# 10$ & $\begin{array}{l}\text { (warfarin or coumadin or acenocoumarol or Rivaroxaban or edoxaban or Apixaban or dabigatran or anticoagula* or anti-coagu- } \\
\mid \mathrm{la}^{*} \text { ).ab,du,kw,ti,tn. }\end{array}$ \\
\hline$\# 11$ & or/\#9-\#10 \\
\hline$\# 12$ & (oral* or DOAC).ab,kw,ti. \\
\hline$\# 13$ & $\# 5$ and \#8 and \#11 and \#12 \\
\hline SCOPUS & $\begin{array}{l}\text { ( TITLE-ABS-KEY ( osteopor* OR fracture* OR ( bone W/2 density ) ) AND TITLE-ABS-KEY ( fibril* OR afib OR af ) AND TITLE- } \\
\text { ABS-KEY ( warfarin OR coumadin OR acenocoumarol OR rivaroxaban OR edoxaban OR apixaban OR dabigatran OR antico- } \\
\text { agula* OR anti-coagula* ) AND TITLE-ABS-KEY ( oral* OR doac ) ) 144 }\end{array}$ \\
\hline
\end{tabular}


Dibbendhu Khanra, et al.

Supplementary Appendix 2. Critical appraisal of the studies

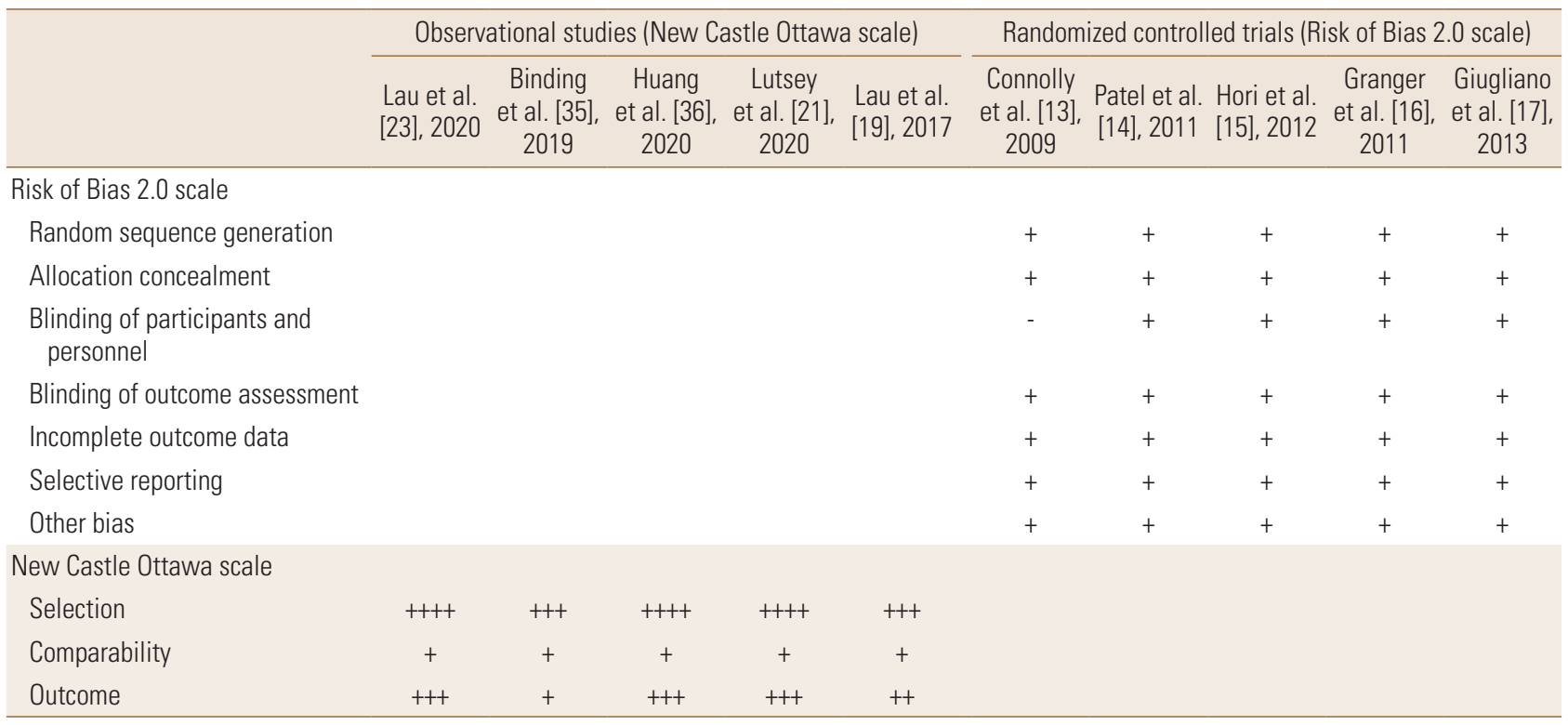




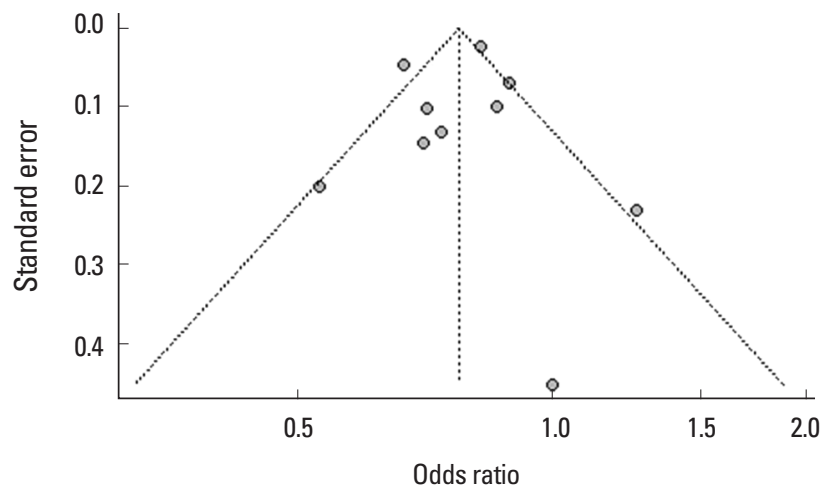

Supplementary Appendix 3. Funnel plot comparing osteoporotic fractures between direct oral anticoagulant and vitamin $\mathrm{K}$ antagonists. 


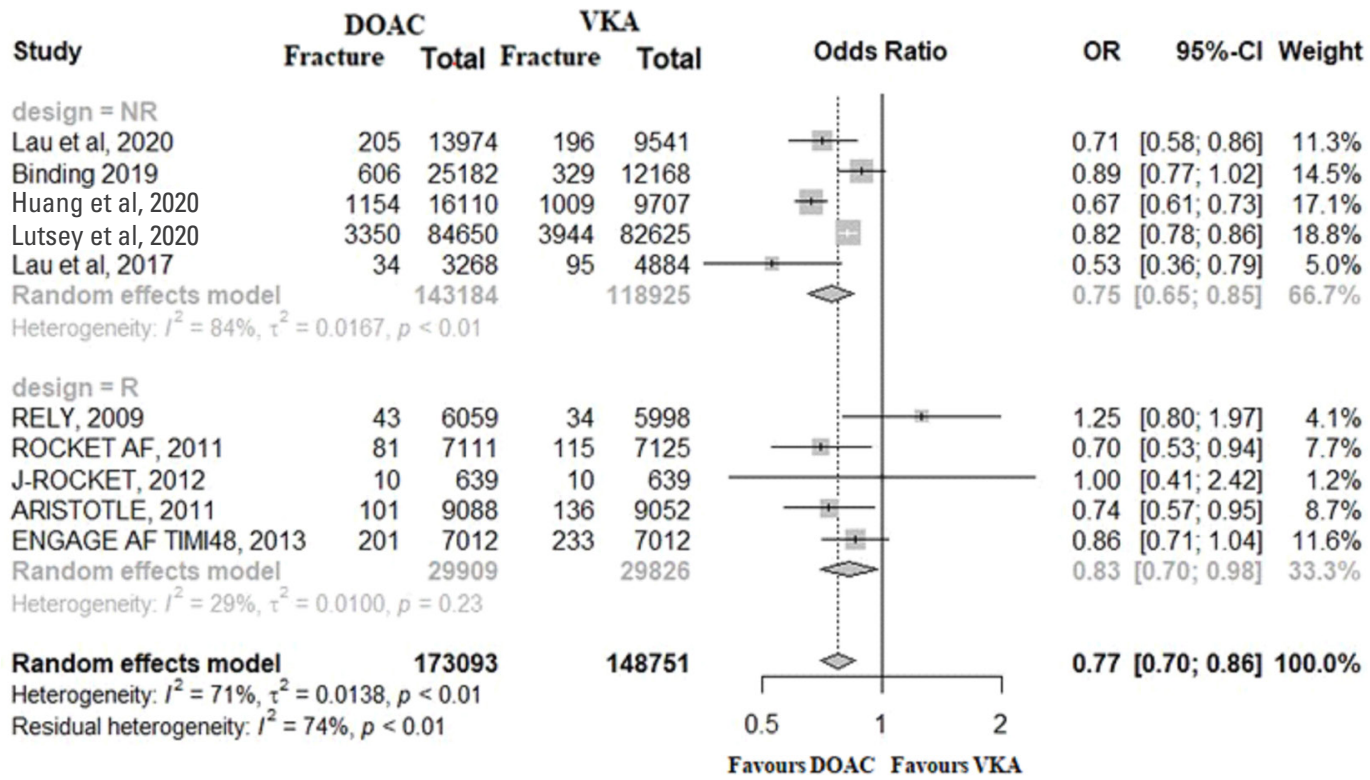

Supplementary Appendix 4. Subgroup analysis osteoporotic fractures comparing direct oral anticoagulant vs. vitamin K antagonists with respect to design of the studies. NR, non-randomized studies; $\mathrm{R}$, randomized studies, OR, odds ratio; $\mathrm{Cl}$, confidence interval. 


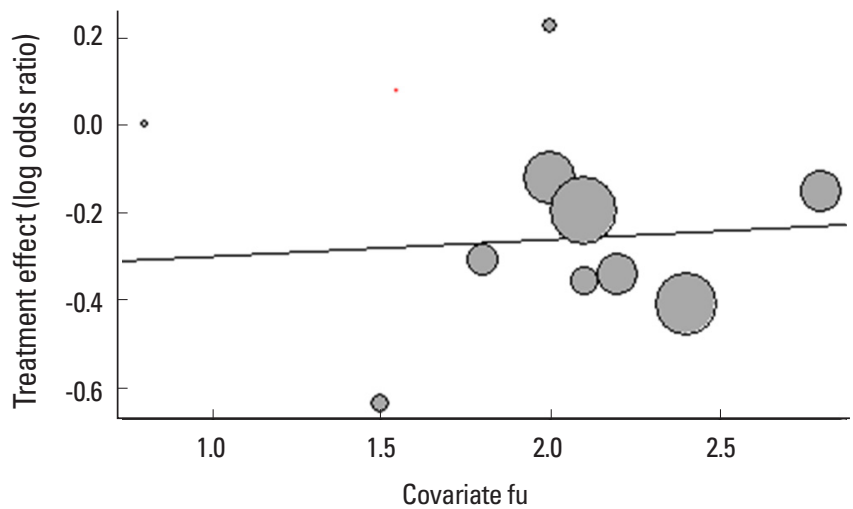

Supplementary Appendix 5. Bubble plot for osteoporotic fractures with respect to the follow-up (fu) duration of the studies. 


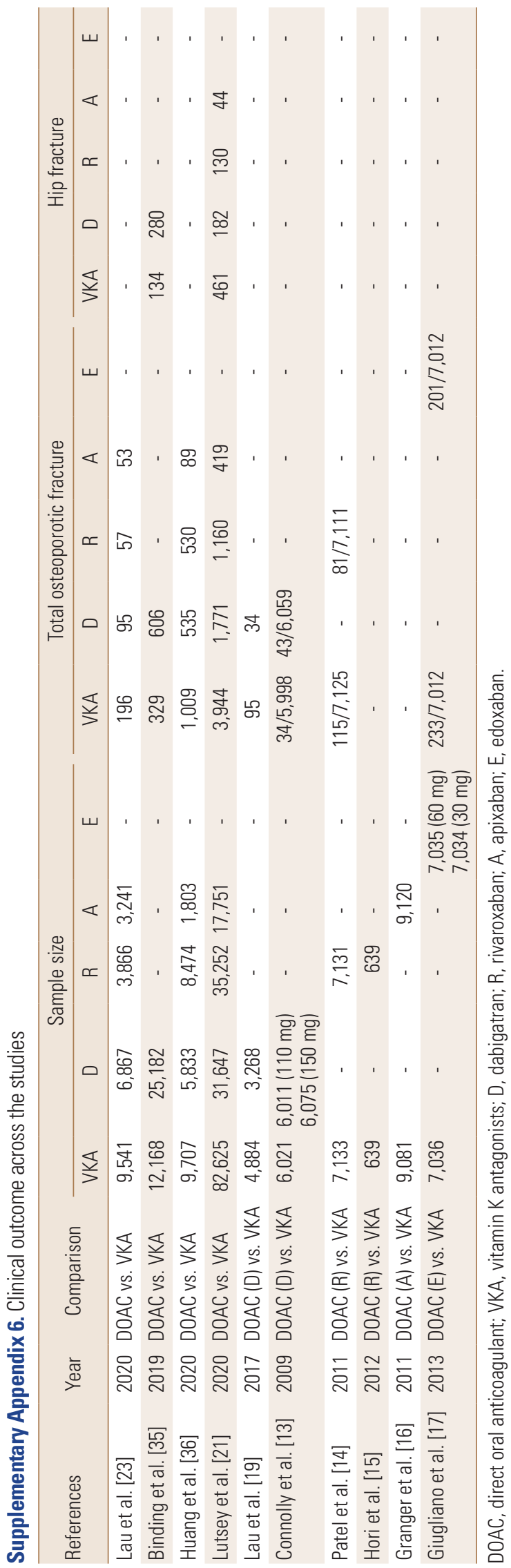




\begin{tabular}{lll}
\hline comparison & p.value & Crl \\
\hline d.Apixaban.Dabigatran & 0.478625 & NA \\
\hline$\rightarrow$ direct & NA & $0.50(-0.069,1.0)$ \\
\hline$\rightarrow$ indirect & NA & $0.077(-1.1,1.3)$ \\
\hline$\rightarrow$ network & NA & $0.45(0.049,0.82)$ \\
\hline d.Apixaban.Rivaroxaban & 0.766125 & NA \\
\hline$\rightarrow$ direct & NA & $0.19(-0.27,0.63)$ \\
\hline$\rightarrow$ indirect & NA & $0.049(-0.92,1.1)$ \\
\hline$\rightarrow$ network & NA & $0.17(-0.21,0.56)$ \\
\hline d.Dabigatran.Rivaroxaban & 0.524000 & NA \\
\hline$\rightarrow$ direct & NA & $-0.33(-0.81,0.18)$ \\
\hline$\rightarrow$ indirect & NA & $-0.024(-0.97,0.95)$ \\
\hline$\rightarrow$ network & NA & $-0.28(-0.63,0.11)$
\end{tabular}

Supplementary Appendix 7. Node-split model for assessment of inconsistency between direct and indirect comparison in all studies: for each treatment comparison that has both direct and indirect estimates, the analysis provides the mean and credible intervals (the value at $2.5 \%$ and $97.5 \%$ quantiles) for the direct, indirect and network estimates together with a Bayesian $P$-value for the related test of inconsistency between the direct and indirect evidence for each treatment comparison. NA, not available; $\mathrm{Crl}$, credible interval. 
d.VKA.Apixaban

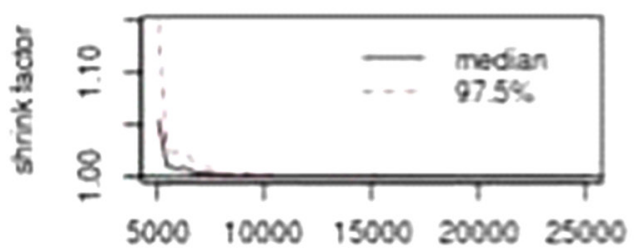

last iseraton in chair

d. VKA.Edoxaban

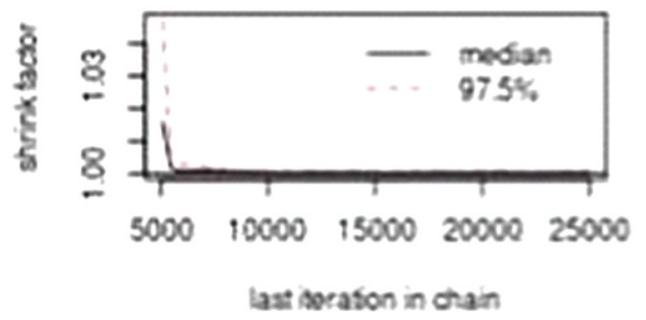

d.VKA.Dabigatran

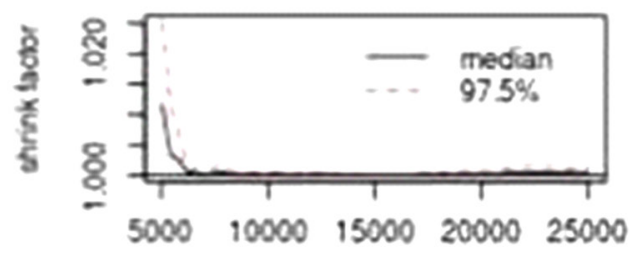

Last deraton in chain

dVKA.Rivaroxaban

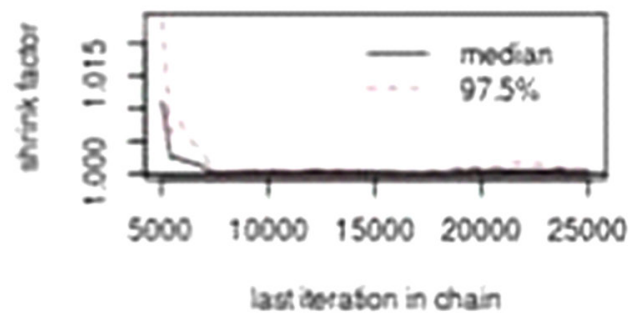

Supplementary Appendix 8. Gelman-Rubin convergence assessment plots for the Bayesian network meta-analysis model showing the red lines on the plot reached stability around the value 1 which suggests that the simulated model has converged. 


\begin{tabular}{|c|c|c|c|c|}
\hline & {$[, 1]$} & ] $[, 2]$ & {$[, 3]$} & {$[, 4]$} \\
\hline ARISTOTLE, 2011 & 1.0187176 & 60.9764725 & & NA \\
\hline ENGAGE, 2013 & 0.9953815 & 50.9992926 & & NA \\
\hline Huang,2020 & 0.9479471 & 10.9893049 & 90.995077 & 40.9995668 \\
\hline JROCKET, 2012 & 0.9170931 & 10.8088935 & & A $\quad N A$ \\
\hline Lau, 2017 & 1.2797572 & 21.1980460 & & IA NA \\
\hline Lau, 2020 & 1.4706977 & 71.2236514 & 40.8526145 & 50.9343715 \\
\hline Lutsey et al, 2020 & 1.0301952 & 21.0220928 & 80.989447 & 80.9884211 \\
\hline RELY, 2009 & 1.0455638 & 80.9493534 & & IA NA \\
\hline \multirow[t]{2}{*}{ ROCKET , 2011} & 0.9078809 & 90.9325679 & & NA \\
\hline & {$[, 1]$} & {$[, 2]$} & {$[, 3]$} & {$[, 4]$} \\
\hline ARISTOTLE, 2011 & 1.0245388 & 0.9828203 & NA & NA \\
\hline ENGAGE , 2013 & 1.0053376 & 1.0022018 & NA & NA \\
\hline Huang,2020 & 0.9036597 & 0.97666250 & 0.98623690 & 0.9908165 \\
\hline JROCKET, 2012 & 0.8982693 & 0.8075035 & NA & NA \\
\hline Lau, 2017 & 1.0907947 & 1.0896815 & NA & NA \\
\hline Lau, 2020 & 1.3304548 & 1.21751370 & 0.89731880 & 0.9584934 \\
\hline Lutsey, 2020 & 0.9897218 & 1.01551620 & 0.99492830 & 0.9926652 \\
\hline RELY, 2009 & 1.2053487 & 1.0980448 & NA & NA \\
\hline ROCKET, 2011 & 0.9640766 & 0.9976874 & NA & NA \\
\hline
\end{tabular}

Supplementary Appendix 9. Residual deviances for each trial arm from the (A) primary network meta-analysis model and from (B) the unrelated mean effect inconsistency model. 


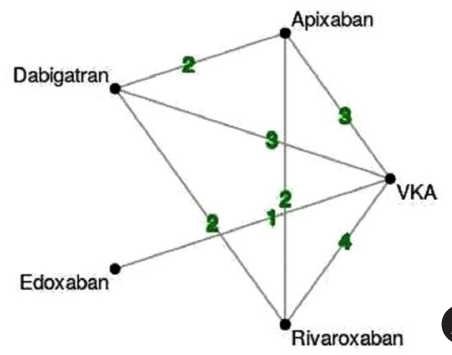

\begin{tabular}{lllllll} 
& & Apixaban & Dabigatran & Edoxaban & Rivaroxaban & VKA \\
\cline { 3 - 7 } & Apixaban & Apixaban & $2.09(1.49,2.89)$ & $1.61(0.87,2.83)$ & $1.29(0.94,1.78)$ & $1.87(1.37,2.43)$ \\
\hline Dabigatran & $0.48(0.35,0.67)$ & Dabigatran & $0.77(0.42,1.35)$ & $0.62(0.45,0.85)$ & $0.89(0.66,1.17)$ \\
\hline Edoxaban & $0.62(0.35,1.15)$ & $1.3(0.74,2.38)$ & Edoxaban & $0.8(0.46,1.47)$ & $1.17(0.7 .1 .95)$ \\
\hline Rivaroxaban & $0.78(0.56,1.07)$ & $1.62(1.17,2.21)$ & $1.24(0.68,2.17)$ & Rivaroxaban & $1.45(1.08,1.85)$ \\
A A & VKA & $0.53(0.41,0.73)$ & $1.12(0.86,1.52)$ & $0.86(0.51,1.43)$ & $0.69(0.54,0.93)$ & VKA
\end{tabular}

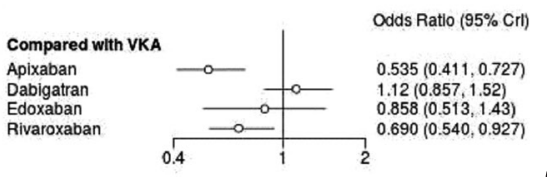

\begin{tabular}{lccccc} 
& Rank 1 & Rank 2 & Rank 3 & Rank 4 & Rank 5 \\
\hline Apixaban & 0.90876 & 0.07965 & 0.01064 & 0.00084 & $0.00 \mathrm{C}$ \\
\hline Dabigatran & 0.00013 & 0.00258 & 0.06549 & 0.19079 & 0.741 \\
\hline Edoxaban & 0.04972 & 0.15200 & 0.53630 & 0.13184 & 0.130 \\
\hline Rivaroxaban & 0.04126 & 0.76194 & 0.18680 & 0.00854 & 0.001 \\
\hline VKA & 0.00013 & 0.00384 & 0.20078 & 0.66800 & 0.127
\end{tabular}

B

C

\begin{tabular}{lll}
\hline comparison & p.value & Crl \\
\hline d.Apixaban.Dabigatran & 0.4813 & NA \\
\hline$\rightarrow$ direct & NA & $0.82(0.43,1.1)$ \\
\hline$\rightarrow$ indirect & NA & $0.54(-0.30,1.4)$ \\
\hline$\rightarrow$ network & NA & $0.74(0.41,1.1)$ \\
\hline d.Apixaban.Rivaroxaban & 0.4788 & NA \\
\hline$\rightarrow$ direct & NA & $0.31(-0.15,0.74)$ \\
\hline$\rightarrow$ indirect & NA & $0.028(-0.79,0.92)$ \\
\hline$\rightarrow$ network & NA & $0.25(-0.061,0.57)$ \\
\hline d.Dabigatran.Rivaroxaban & 0.9748 & NA \\
\hline$\rightarrow$ direct & NA & $-0.49(-0.96,-0.0030)$ \\
\hline$\rightarrow$ indirect & NA & $-0.50(-1.4,0.50)$ \\
\hline$\rightarrow$ network & NA & $-0.48(-0.79,-0.17)$
\end{tabular}

\begin{tabular}{|cc|}
\hline Rank & Intervention \\
\hline 1 & Apixaban \\
\hline 2 & Rivaroxaban \\
\hline 3 & Edoxaban \\
\hline 4 & VKA \\
\hline 5 & Dabigatran \\
\hline
\end{tabular}

Supplementary Appendix 10. Sensitivity analysis excluding Lau et al. [19] and Lau et al. [23]: (A) network plot, (B) Bayesian comparison of all treatment pairs, (C) funnel plot, (D) ranking probability table, (E) node-split model for assessment of inconsistency, (F) median rank chart. VKA, vitamin $\mathrm{K}$ antagonists; Crl, credible interval. 


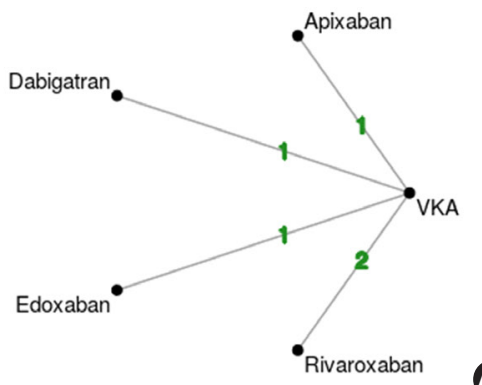

(A)

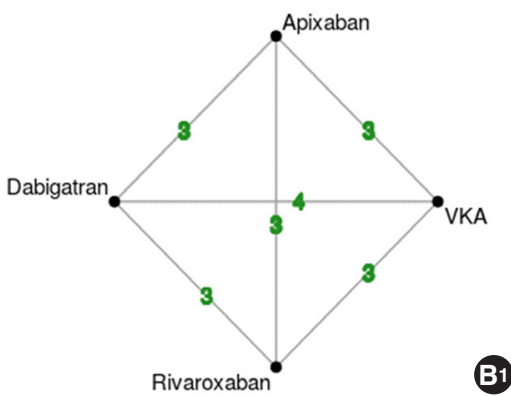

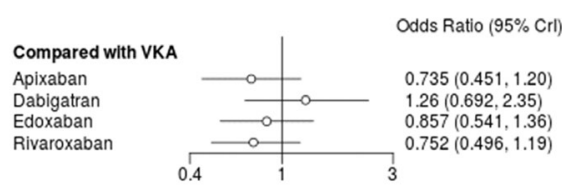

A2
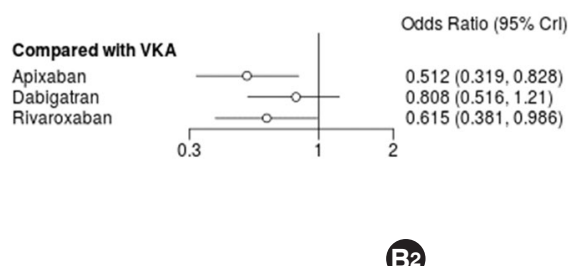

B2

\begin{tabular}{|cc|}
\hline Ra'lk & Inlervention \\
\hline 1 & \\
\hline 2 & $\begin{array}{c}\text { Apixaban } \\
\text { Rivaroxaban }\end{array}$ \\
\hline 3 & Edoxaban \\
\hline 4 & VKA \\
\hline 5 & Dabigatran \\
\hline
\end{tabular}

\begin{tabular}{|cc|}
\hline Rank & Intorvention \\
\hline 1 & Apixaban \\
\hline 2 & Rivaroxaban \\
\hline 3 & Dabigatran \\
\hline 4 & VKA \\
\hline
\end{tabular}

B3

Supplementary Appendix 11. Sub-group network meta-analysis with randomized controlled trials only (A) and with population-based studies only (B). Network plot (A1, B1), forest plot (A2, B2), median rank chart (A3, B3). VKA, vitamin K antagonists; Crl, credible interval. 